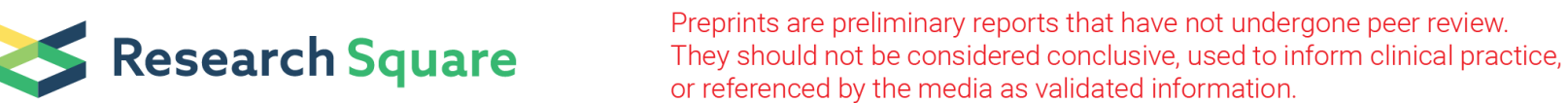

\section{Assessing the feasibility of a social worker-led non- communicable disease self-management intervention for low-income women elderly: a pilot trial}

\section{Xueji Wu}

Guangzhou Center for Disease Control and Prevention https://orcid.org/0000-0002-0252-2545

\section{Xiongfei Chen}

Guangzhou Center for Disease Control and Prevention

\section{Bingying Pan}

Guangzhou Center for Disease Control and Prevention

\section{Lan Liu}

Guangzhou Center for Disease Control and Prevention

\section{Xiaomei Dong}

Jinan University

\section{Wanwen $\mathrm{Yu}$}

Qichuang social work service

\section{David L. Parker}

HealthPartners Institute

\section{Bagen Liao}

Guangzhou Sport University

Min Hu ( $\nabla$ whoomin@hotmail.com )

Guangzhou Sport University

\section{Research article}

Keywords: Health care policy, Social work, Health disparities, Health outcome

Posted Date: February 16th, 2021

DOl: https://doi.org/10.21203/rs.3.rs-234683/v1

License: (1) This work is licensed under a Creative Commons Attribution 4.0 International License. Read Full License 


\section{Abstract}

\section{Background}

Low-income Chinese women aged 60 years and older are more likely to have multiple non-communicable diseases (NCDs). Neither the independent healthcare system nor the social work system based on the communities is equipped to address their complex needs of health and daily care. The objective was to design and evaluate a social worker-led self-management program for older community-dwelling women with NCDs.

\section{Methods}

A total of 144 and 138 subjects were recruited in the intervention and control groups from 10 communities in Guangzhou, China. The intervention group was designed as follows: each community recruited two social workers to carry out an NCD self-management program. A health care professional assisted social workers to complete six weekly two-hour sessions. The control group had no extra intervention. The evaluation was conducted at baseline and 12-months follow-up. Outcomes included changes in weight, blood pressure, fasting plasma glucose (FPG), lipid profile, self-management behaviors, and NCD-related knowledge.

\section{Results}

After 12 months, participants had gained 3.6 and $6.6 \mathrm{~kg}$ ( $P=0.025$ for between-group difference) in the intervention and control groups, respectively. NCD-related knowledge increased by $15.4 \%$ and $11.3 \%$ ( $P<0.001$ for between-group difference). The intervention group had a greater increase in self-reported exercise $(87 \%$ to $95 \%)$ than the control group $(81 \%$ to $85 \%)$ ( $P$ difference $=0.031)$. General linear regression analysis showed that the intervention effects were significant for FPG $(P=0.013)$ and total cholesterol (TC) $(P=0.046)$.

\section{Conclusions}

A social worker-led NCD self-management program successfully promoted NCD-related knowledge and decreased metabolic risk factors in low-income Cantonese women.

\section{Trial registration}

Chinese Clinical Trial Registry:Evaluation on effectiveness of Non-communicable Disease Selfmanagement models led by social organization. ChiCTR1800015659. Registered 13 April 2018 Retrospectively registered, http://www.chictr.org.cn/showproj.aspx?proj=15005

\section{Background}


China's population is aging at an extraordinarily high speed. At this time, non-communicable diseases (NCDs) account for nearly $70 \%$ of deaths of Chinese women[1]. Nationwide, the prevalence of hypertension[2], diabetes[3], and high triglycerides and total cholesterol[4] is greater in women aged 60 years than in their male peers. Low socioeconomic status[5], behavioral factors (e.g. smoking, excessive use of alcohol, physical inactivity, unhealthy diet) as well as biological factors (e.g., menopause)[6] contribute to women's high prevalence of NCDs. Chinese elder women have fewer opportunities than men do to pursue NCD self-management due to lower educational attainment[7] and are less likely to seek medical care until urgent intervention is necessary[8]. According to the $6^{\text {th }}$ National population census (2010), nearly $95 \%$ Chinese old women had education attainment less than 9 years, less than $50 \%$ were financial independent, and 15\% reported that they were unhealthy but can live on their own. With the development of social-economics, China has introduced social work for assisting vulnerable group since the 1990s. Social workers on primary care teams have successfully addressed a wide range of problems, including those related to geriatric health[9].

Patient-centered self-management education is an effective and low-cost means of addressing chronic disease management[10]. Providing feedback on performance, problem-solving, and action planning are promising behavioral change techniques in self-management education[11], although findings regarding utilization and cost benefits are mixed. Inner setting, characteristics of individuals and intervention characteristics is main ingredients for implementing intensive outpatient programs within patientcentered medical homes[12].

Guangzhou is the largest city in southern China and has 1.55 million people aged 60 years or older, of whom $51 \%$ are women. The city has 188 administrative blocks in which 2450 registered social workers provide services. Since 2009, the local hygiene administration department has developed policies to support primary health care centers for older people. However, in spite of ongoing outreach efforts, the decrease trend of self-reported health conditions in older women rose higher than men from 20102015[13].

In 2013, the Guangzhou government initiated a new program, "Build a Healthy City: 2013-2020." In the program, social workers are encouraged to collaborate with health care professionals in NCD selfmanagement to improve patient adherence to clinical recommendations and self-care. This manuscript presents findings from a pilot intervention targeting low-income women aged 60 and older with hypertension, type 2 diabetes, and/or dyslipidemia.

\section{Methods}

The intervention was implemented at 10 primary health care centers. Each center organized one NCD selfmanagement group consisting of social worker group leaders and one health care provider consultant. Participating staff members were fluent in Mandarin and Cantonese. Group leaders completed a 16-hour NCD self-management training course and passed an assessment exam. Training included an 
introduction to the program and NCDs, diet, physical activity, medication use, group communication and facilitation, role-play, and group dynamics.

Subject recruitment took place via referral from health care providers, friends, and public service announcements. Exclusion criteria included serious mental illness, brain injury, dementia, cancer, language barriers, and serious complications of NCDs. Inclusion criteria included: (1) having a medical record in a participating primary health care center; (2) female aged 60 to 80 years and income $<5000$ $\mathrm{RMB} /$ month; (3) living in the local area for six or more months; and (4) suffering from hypertension and/or type 2 diabetes and/or dyslipidemia. Controls were matched by age and sex and had at least one of the stated chronic conditions (e.g., hypertension). There were 12 to 15 participants in each group. The final study consisted of 144 and 138 individuals in the intervention and control groups, respectively. During the study period, all participants continued to receive their usual health care.

The intervention was carried out from June 1 to August 1, 2016 and comprised six two-hour weekly sessions. The content of each session is listed in Table 1. Group leaders were asked to follow the designed program. Before each session, group leaders briefly assessed the medical status of participants and updated their health records. Two individuals observed each session to assess intervention fidelity. Group leaders were not allowed to prepare the next session before correcting problems observed during their previous presentations. In the year after the intervention, group leaders maintained weekly contact with participants by providing social assistance services such as organizing community entertainment. 


\begin{tabular}{|c|c|c|}
\hline Session & Topic areas & Outcome goals \\
\hline \multirow[t]{2}{*}{$\begin{array}{l}\text { Session } \\
1\end{array}$} & $\begin{array}{l}\text { Overview of } \\
\text { noncommunicable diseases } \\
\text { (NCDs) }\end{array}$ & $\begin{array}{l}\text { Introduce participants. Provide overview of } \\
\text { noncommunicable diseases. }\end{array}$ \\
\hline & $\begin{array}{l}\text { Setting goals and creating } \\
\text { an action plan }\end{array}$ & $\begin{array}{l}\text { Introduce and explain the importance of setting goals and } \\
\text { creating an NCD self-management plan. }\end{array}$ \\
\hline $\begin{array}{l}\text { Session } \\
2\end{array}$ & Meal planning & $\begin{array}{l}\text { Understand the relationship between diet, caloric intake, } \\
\text { healthy cooking, and good health. }\end{array}$ \\
\hline $\begin{array}{l}\text { Session } \\
3\end{array}$ & $\begin{array}{l}\text { Introduction to exercise and } \\
\text { relaxation techniques }\end{array}$ & $\begin{array}{l}\text { Understand the benefits of aerobic exercise and develop } \\
\text { an exercise plan. Practice muscle relaxation techniques. }\end{array}$ \\
\hline $\begin{array}{l}\text { Session } \\
4\end{array}$ & $\begin{array}{l}\text { Pharmacologic treatment } \\
\text { and medication } \\
\text { management }\end{array}$ & $\begin{array}{l}\text { Understand the role of pharmacologic treatment in the } \\
\text { management of NCDs. }\end{array}$ \\
\hline \multirow{3}{*}{$\begin{array}{l}\text { Session } \\
5\end{array}$} & Communication skills & \multirow[t]{2}{*}{ Practice communication skills and relaxation techniques. } \\
\hline & Relaxation practices & \\
\hline & $\begin{array}{l}\text { How to deal with negative } \\
\text { emotions }\end{array}$ & Learn to manage negative emotions. \\
\hline \multirow[t]{3}{*}{$\begin{array}{l}\text { Session } \\
6\end{array}$} & Smoking cessation & $\begin{array}{l}\text { Recognize the dangers of tobacco use and understand } \\
\text { options for quitting. }\end{array}$ \\
\hline & Increasing self-efficacy & $\begin{array}{l}\text { Introduce self-efficacy and how it can enhance NCD self- } \\
\text { management. }\end{array}$ \\
\hline & Closing & Create an individualized self-management plan. \\
\hline
\end{tabular}

About one week before the first session, data were collected on participants' socioeconomic status (SES), disease history, diet, exercise habits, weight, systolic blood pressure (SBP), diastolic blood pressure (DBP), fasting plasma glucose (FPG), lipid profile (TG, triglycerides; TC, Total cholesterol; HDL, High-density lipoprotein cholesterol; LDL, Low-density lipoprotein cholesterol). Phlebotomy was declined by 114 of 282 participants ( 57 from the intervention group and 57 from the control group). At baseline, no significant differences were observed between the two groups. NCD-related knowledge was assessed at baseline and 12-month follow-up using a 10-question survey.

Data were analyzed using EpiData version 3.0 (EpiData Association, Odense, Denmark). Summary statistics were expressed as mean \pm standard deviation (SD), percentage, median, or range (minimum, maximum) as appropriate. t-tests were used for continuous variables following normal distribution, while the nonparametric Mann-Whitney test was used for nonnormal distribution data, and chi-square tests were for binomial distribution data. The McNemar test and chi-square tests were used to assess withinand between-group comparisons for categorical variables. General linear regression and logistic regression were used for comparing changes in continuous and binary outcomes from baseline to the 
12th month between groups. All statistical analyses were performed using SPSS Statistics (Version 19.0, SPSS, Inc., Chicago, IL).

\section{Results}

Twenty social workers with an average age of 35 years $(S D=11)$ were recruited, of whom $14(70 \%)$ were women. None had previously acted in a similar capacity as a group leader in an NCD self-management program. At the end of the program, 16 of 20 said that the program was a useful addition to their daily work.

There were minimal baseline differences between the intervention and control groups (Table 2). Overall, $25(17 \%)$ and $28(20 \%)$ of individuals in the intervention and control groups, respectively, were lost to follow-up $(P=0.520)$. There were minimal differences between the characteristics of individuals who were or were not lost to follow-up. 


\section{Table 2. Baseline characteristics for intervention and control groups}

Characteristics

$\mathrm{N}$

\section{Demographics}

Age

High school or above

Urban area

Hospitalized during the past year

\section{Self-reported chronic disease}

Hypertension

Type 2 diabetes

Hypertension duration

Type 2 diabetes duration

Treatment for hypertension

Treatment for type 2 diabetes

NCD-related knowledge score

Self-management behaviors

Current smoking

Current drinking

Days of eating healthy food during the past week*

Aerobic exercise ( $\geq 30 \mathrm{~min} /$ day)

\section{Physiological measures}

Weight $(\mathrm{kg})$

SBP $(\mathrm{mm} \mathrm{Hg})$

DBP $(\mathrm{mm} \mathrm{Hg})$

$\mathrm{N}$ for blood tests

FPG $(\mathrm{mg} / \mathrm{dL})$

$\mathrm{TG}(\mathrm{mg} / \mathrm{dL})$

\begin{tabular}{ll} 
Intervention group & Control group \\
\hline Mean (SD) or \% & Mean (SD) or \% \\
\hline 144 & 138
\end{tabular}

$66.4(4.3)$

$67.5(5.5)$

0.067

$30.60 \%$

$30.40 \%$

0.982

$72.70 \%$

$70.10 \%$

0.623

$20.10 \%$

$9.40 \%$

0.011

$84.80 \%$

$86.10 \%$

0.752

$55.60 \%$

3.1 (1.1)

$44.90 \%$

0.074

$3.2(1.1)$

0.735

3.2 (1.1)

$3.0(1.2)$

0.486

$93.50 \%$

$94.10 \%$

0.854

$95.10 \%$

$93.70 \%$

0.714

40.6 (12.6)

37.7 (15.0)

0.080

$2.80 \%$

$1.40 \%$

0.440

$2.10 \%$

$5.80 \%$

0.107

$2(0,7)$

$2(0,7)$

0.097

$86.80 \%$

$81.20 \%$

0.196

58.5 (8.2)

59.3 (10.0)

0.420

139.4 (17.0)

138.6 (15.1)

0.679

80.1 (10.4)

$79.2(10.2)$

0.504

87

81

117.5 (38.0)

110.4 (53.4)

0.206

$144.9(85.6)$

$140.6(92.3)$

0.752 


\begin{tabular}{|lllr|}
\hline TC (mg/dL) & $211.3(45.8)$ & $215.3(48.4)$ & 0.586 \\
\hline HDL (mg/dL) & $58.0(18.6)$ & $62.0(23.6)$ & 0.215 \\
\hline LDL (mg/dL) & $124.6(37.1)$ & $123.7(39.1)$ & 0.881 \\
\hline * Median (minimum, maximum) & & \\
$\begin{array}{l}\text { Abbreviations: SBP, systolic blood pressure; DBP, diastolic blood pressure; FPG, fasting plasma } \\
\text { glucose; TG, triglycerides; TC, Total cholesterol; HDL, High-density lipoprotein cholesterol; LDL, Low- } \\
\text { density lipoprotein cholesterol. }\end{array}$ & \\
\hline
\end{tabular}

Table 3 shows the results of within- and between-group analyses. The within-group analyses show that the intervention group had a $15.4 \%(P<0.001)$ and the control group an $11.3 \%(P<0.001)$ increase in their NCD-related knowledge scores ( $P$ difference $=0.204)$. The intervention and control groups had a 3.6 $(P=0.009)$ and $6.6 \mathrm{~kg}(P<0.001)$ increase, respectively, in weight. The intervention group increased its aerobic exercise rate from $86.8 \%$ to $94.8 \%(P=0.031)$ but had no significant differences in physiological measures. Similarly, the control group increased its aerobic exercise rate from $81.2 \%$ to $84.5 \%(P=0.484)$. However, the control group had a $4.5 \%$ increase in eating healthy food $(P=0.001)$ and an increase of $0.6 \mathrm{mmol} / \mathrm{L}(10.0 \mathrm{mg} / \mathrm{dL})$ in FPG $(P=0.020)$. 
Table 3 Changes in noncommunicable disease-related knowledge score, self-management behaviors and physiological measures

Characteristics Intervention group

Control group

$P^{*}$

\begin{tabular}{|c|c|c|c|c|c|}
\hline Baseline & 12 & $P$ for & Baseline & 12 & \\
\hline & & $A_{t 1} v s$. & & & $\mathrm{B}_{\mathrm{t} 1}$ vs. \\
\hline$\left(A_{t 1}\right)$ & $\left(A_{t 2}\right)$ & & $\left(B_{t 1}\right)$ & $\left(B_{t 2}\right)$ & \\
\hline
\end{tabular}

NCD-related

knowledge

$\begin{array}{ll}41.1(12.1) & 56.5 \\ & (19.1)\end{array}$

$<0.001 \quad 37.7(15.0)$

$49.0(19.5) \quad<0.001 \quad 0.204$ \#\#

Self-management behaviors

Current smoking $\quad 2.80 \%$

$(\%)$

1

$(0.8 \%)$

$0.382 \quad 1.40 \%$

$1(0.9 \%)$

1.000

0.995

Current drinking

(\%)

$2.10 \%$

$3 \quad 1.000 \quad 5.80 \%$

$4(3.8 \%)$

0.557

0.121

Days of eating

$2(0,7)$

$(2.5 \%)$

healthy food

$3(0,7)$

$0.076 \quad 2(0,7)$

$3(0,7)$

0.002

0.721

during the past

week

$\begin{array}{llllllll}\begin{array}{l}\text { Aerobic exercise } \\ (\geq 30 \mathrm{~min} / \text { day })\end{array} & 86.80 \% & 94.8 \%{ }^{\#} & \mathbf{0 . 0 2 5} & 81.20 \% & 84.50 \% & 0.484 & 0.095\end{array}$

\section{Physiological}

measures

Weight $(\mathrm{kg})$

Weight (kg)

$\operatorname{SBP}(\mathrm{mm} \mathrm{Hg})$

$\mathrm{DBP}(\mathrm{mm} \mathrm{Hg}) \quad 80.5$

(10.7)

58. 7 (8.2)

62.2

(8.1)

138. 4

(15.9)

138.0

(17.3)

79.8

(10.4) $\mathbf{0 . 0 0 9} \quad 58.2(8.3)$

$64.8(9.2)$

$<0.001$

0.113

$0.803 \quad 138.7(16.3)$

135.9

(13.7)

$0.103 \quad 0.638$

0.511

80. 1 (10.6)

$78.2(9.5)$

0.117

0.543

87

81

77

0.665

$\mathrm{N}$ for blood tests

87

6.5

(2.1)

$6.6(2.1)$

0.459

$6.1(2.4)$

$6.7(2.4)$

0.02

0.013

FPG (mg/dL)

117.5

(38.0)

117.0

(39.6)

0.459

110.4

(53.4)

144.9

(85.6)

$\mathrm{TC}(\mathrm{mg} / \mathrm{dL})$

211.3

(45.8)
161.1

(136.6)

200.1

(51.6)
0.081

140.6

(92.3)

0.112

215.3

(48.4)

Page 9/15
120.4

(43.2)

0.02

0.013

144.4

(98.6)

0.759

0.338

200.3

(56.1)

0.164

0.046 
self-management intervention. However, members of the intervention group did not improve their dietary pattern. It is noteworthy that there is substantial variability and complexity in Cantonese cuisine[17], a problem compounded by social workers' limited knowledge of nutrition.

Poor health-related knowledge is often observed in older women and poorly educated individuals[18]. Due to social instability, poverty, and tradition, previous generations of Chinese women have had limited educational opportunities. Low levels of literacy are linked with low levels of health literacy, which in turn adversely affects the development of self-management skills[19].

A recent review concluded that self-management interventions are effective in adults with low health literacy and a chronic physical illness[20]. Low educational attainment and having experienced poverty and/or famine during the 1960s likely explain why older women often do not manage their weight or have misconceptions about maintaining a healthy weight[21]. However, in our study, although both groups gained weight, the intervention group gained less than the control group.

Little research had explored social worker feedback in providing services to older populations with multiple NCDs. With industrial and social development, in 2007, Guangzhou was the first city in China to implement social work into health care. Feedback from participants showed that they were satisfied with their participation. Over $75 \%$ indicated that they would participate in the self-management program again. In addition, 16 of $20(80.0 \%)$ of social workers said that the program was useful. These data suggest that the program should be expanded.

This study was limited by a small sample size that was reduced by participant fear of phlebotomy. Future work should include finding ways to enhance full participation as well as improve understanding of diet in both participants and social workers. Training programs conducted by the China Initiative for Diabetes Excellence (unpublished) included small models of popular dishes to help demonstrate portion size and carbohydrate content. These models were useful in training clinicians about the complexity and variability of the Chinese diet. Other changes might include ensuring that there is no crossover effect. In the current study, intervention and control participants came from the same clinics, which may have limited the apparent impact of the intervention.

\section{Conclusions}

A social worker-led NCD self-management program successfully promoted NCD-related knowledge and decreased metabolic risk factors in low-income Cantonese women.

\section{Abbreviations}




\begin{tabular}{|ll|}
\hline NCDs & non-communicable diseases \\
\hline FPG & fasting plasma glucose \\
\hline TC & total cholesterol \\
\hline SES & socioeconomic status \\
\hline SBP & systolic blood pressure \\
\hline DBP & diastolic blood pressure \\
\hline TG & triglycerides \\
\hline HDL & High-density lipoprotein cholesterol \\
\hline LDL & Low-density lipoprotein cholesterol \\
\hline
\end{tabular}

\section{Declarations}

\section{Ethics approval and consent to participate}

All the study participants gave informed consent, and the study received approval from the human subjects review board of the Guangzhou Centers for Disease Control and Prevention with approval number 2013006.

\section{Consent for publication}

Not applicable.

\section{Competing interests}

The authors declare that they have no competing interests.

\section{Funding}

This work is supported by grants from the National Key Research and Development Program of the Ministry of Science and Technology, China (2020YFC2002900) and Guangzhou Medical Science Program, Guangzhou, Guangdong, China(No. 20151A01105).

\section{Authors' contributions}

Xueji Wu carried out the study and draft the manuscript. Xiongfei Chen conceived the study and participated in the study design and analyzed the data. Bingying Pan and Dong Xiaomei organized the program Lan Liu carried out the data analyses and conducted site supervision. Wanwen Yu and Bagen Liao trained social workers and participated in the study design. David L. Parker and Min Hu amended the manuscript. 
Acknowledgements

The authors are grateful for social workers and health care professionals from communities.

\section{References}

1.The National Center for Chronic and Noncommunicable Disease Control and Prevention. The data set of National Death Cause Surveillance 2017 (in Chinese). 1st ed. Beijing: China Science and Technology Press; 2018.

2.Lewington S, Lacey B, Clarke R, Guo Y, Kong XL, Yang L, et al. The Burden of Hypertension and Associated Risk for Cardiovascular Mortality in China. JAMA Intern Med. 2016; 176:524-32. https://jamanetwork.com/journals/jamainternalmedicine/fullarticle/2500028

3.Bragg F, Holmes MV, lona A, Guo Y, Du H, Chen Y, et al. Association Between Diabetes and CauseSpecific Mortality in Rural and Urban Areas of China. JAMA. 2017; 317:280-9.

https://jamanetwork.com/journals/jama/fullarticle/2598266

4.Gu T, Zhou W, Sun J, Wang J, Zhu D, Bi Y. Gender and Age Differences in Lipid Profile Among Chinese Adults in Nanjing: a Retrospective Study of Over 230,000 Individuals from 2009 to 2015. Exp Clin Endocrinol Diabetes. 2018; 126:429-36. DOI: 10.1055/s-0043-117417

5.Allen L, Williams J, Townsend N, Mikkelsen B, Roberts N, Foster C, et al. Socioeconomic status and noncommunicable disease behavioural risk factors in low-income and lower-middle-income countries: a systematic review. Lancet Glob Health. 2017; 5: e277-e89. https://doi.org/10.1016/S2214109X(17)30058-X

6.Sanne A E Peters, Mark Woodward, Vivekanand Jha, Stephen Kennedy, Robyn Norton. Women's health: a new global agenda. BMJ Global Health. 2016; 12(3):271-273. http://dx.doi.org/10.1136/bmjgh-2016000080

7.Hao Zhang, TeresaBago d'Uva, Eddyvan Doorslaer. The gender health gap in China: A decomposition analysis. Econ Hum Biol. 2015; 18:13-26. https://doi.org/10.1016/j.ehb.2015.03.001

8.World Health Organization. Women and Health, today's evidence tomorrow's agenda. Geneva Switzerland WHO 2013.

https://apps.who.int/iris/bitstream/handle/10665/44168/9789241563857_eng.pdf?sequence=1

9.Xuanwen Liu, Ying Ping Zhang, Cynthia Franklin, Yuanzhou Qu, Hong Chen, Johnny S. Kim, The Practice of Solution-Focused Brief Therapy in Mainland China, Health and Social Work. 2015; 40(2):8490. https://doi.org/10.1093/hsw/hlv013

10.Michael Vallis, K. Kovacs Burns, Debbie Hollahan, Stuart Ross, Jina Hahn. Diabetes Attitudes, Wishes and Needs Second Study (DAWN2): Understanding Diabetes-Related Psychosocial Outcomes for 
Canadians with Diabetes. Can J Diabetes. 2016; 40:234-41. https://doi.org/10.1016/j.jcjd.2015.11.002

11.Li Cheng, Janet W. H. Sit, Kai-chow Choi, Sek-ying Chair, Xiaomei Li, Xiao-le He. Effectiveness of Interactive Self-Management Interventions in Individuals With Poorly Controlled Type 2 Diabetes: A MetaAnalysis of Randomized Controlled Trials. Worldviews Evid Based Nurs. 2017; 14:65-73. https://doi.org/10.1111/wvn.12191

12.Jessica Y. Breland, Steven M. Asch, Cindie Slightam, Ava Wong and Donna M. Zulman. Key ingredients for implementing intensive outpatient programs within patient-centered medical homes: A literature review and qualitative analysis. Healthcare. 2016; 4:22-9. https://doi.org/10.1016/j.hjdsi.2015.12.005

13.Wenjuan Zhang, Dongjing Wang. The health status and its changes of the Chinese elderly (in Chinese). Population and economics. 2018; 229:90-102.

14.McGregor J, Mercer, Stewart W. Harris, Fiona M. Health benefits of primary care social work for adults with complex health and social needs: a systematic review. Health Soc Care Community. 2018; 26:1-13. https://doi.org/10.1111/hsc.12337

15.Enguidanos S, Coulourides Kogan A, Keefe B, Geron SM, Katz L. Patient-centered approach to building problem solving skills among older primary care patients: problems identified and resolved. J Gerontol Soc Work. 2011; 54:276-91. https://scite.ai/reports/10.1080/01634372.2011.552939

16.Dongbo FY, Ding; Patrick, McGowan; Hua, Fu. Qualitative evaluation of Chronic Disease Self Management Program (CDSMP) in Shanghai. Patient Educ Couns. 2006; 61:389-96. https://doi.org/10.1016/j.pec.2005.05.002

17.Wang H. Discussion on Health Care of Cantonese Cuisine (in Chinese). China Condiment. 2015; 40:108-13.

18.Michael Quartuccio, Eleanor M.Simonsick, Susan Langan, Tamara Harris, Rebecca L.Sudore, Roland Thorpe, et al. The relationship of health literacy to diabetes status differs by sex in older adults. J Diabetes Complications. 2018; 32:368-72. https://doi.org/10.1016/j.jdiacomp.2017.10.012

19.Bas Geboers AFdW, Sophie L. W. Spoorenberg, Klaske Wynia, and Sijmen A. Reijneveld. The association between health literacy and self-management abilities in adults aged 75 and older, and its moderators. Qual Life Res. 2016; 25:2869-77. https://doi.org/10.1007/s11136-016-1298-2

20.Schaffler J, Leung K, Tremblay S, Merdsoy L, Belzile E, Lambrou A, et al. The Effectiveness of SelfManagement Interventions for Individuals with Low Health Literacy and/or Low Income: A Descriptive Systematic Review. Journal of General Internal Medicine. 2018; 33:510-23.

https://doi.org/10.1007/s11606-017-4265-x 
21.Gao C LX, Yin Y, Song Y, Zhang P, Wang R, Jiang L, Wang Y, Yu Y, Li B. Perceptions and behaviours towards high body weight among adults in Northeast China. Public Health Nutrition. 2017; 20:1-7. https://doi.org/10.1017/S1368980017000556

\section{Supplementary Files}

This is a list of supplementary files associated with this preprint. Click to download.

- renamedb39c4.xIsx 